\title{
Industrialised nanocrystalline bainitic steels. Design approach.
}

Carlos Garcia-Mateo $^{\mathrm{a}}$, Francisca G. Caballero ${ }^{\mathrm{a}}$, Thomas Sourmail ${ }^{\mathrm{b}}$, Veronique Smanio ${ }^{\mathrm{b}}$, Carlos Garcia de Andres ${ }^{\mathrm{a}}$.

${ }^{a}$ Department of Physical Metallurgy. National Center for Metallurgical Research (CENIMCSIC), MATERALIA Research Group. Madrid, Spain.

${ }^{\mathrm{b}}$ Ascometal-CREAS (Research Centre) Metallurgy. Hagondange Cedex, France

Nanostructured microstructures consisting of a mixture of very thin plates of bainitic ferrite separated by $\mathrm{C}$ enriched austenite are the main characteristics of the so called NANOBAIN steel family. This paper shows the theoretical approach followed in the design of a new, industrially viable, generation of NANOBAIN steels, a process in which industrial demands such as, simpler chemical compositions, faster transformation kinetics and suffice hardenability have been also considered. The microstructural and mechanical characterization of the bainitic microstructures obtained by isothermal transformation at different temperatures, come to confirm and to validate the theoretical approach used.

Keywords: Nanostructured; Bainite; Thermodynamic theory; Diffusionless 


\section{Introduction}

In the first experiences, bainite phase transformation theory was used for the design of NANOBAIN steels, with the only purpose of obtaining bainite at the lowest possible temperature $[1,2]$. For this purpose the chemical composition was selected to allow bainitic transformation at temperatures as low as $125^{\circ} \mathrm{C}$; NANOBAIN 1 and 2 in Table 1 . At such temperature the transformation required more than 2 months to be completed, and about 10 days at $200{ }^{\circ} \mathrm{C}$, see Table 2. Further development [3] enabled this time to be substantially decreased, and even finer bainitic microstructures were obtained after 3 days at $200{ }^{\circ} \mathrm{C}$; NANOBAIN 3 and 4 in Table 1 and Table 2. Such an improvement was based on two concepts, control of the austenitization conditions previous to bainitic transformation and the addition of Co (1.5 wt.\%), NANOBAIN 3, and Co+Al (1.5+1 wt.\%), NANOBAIN 4, both elements known for increasing the free energy change for transformation $[4,5]$, in other words, known for accelerating transformation kinetics.

The extraordinary combination of mechanical properties, with yield strength $(Y S)$ of $1.4 \mathrm{GPa}$, ultimate tensile strength (UTS) of $2.2 \mathrm{GPa}, 30 \%$ ductility and respectable levels of fracture toughness $\left(\approx 51 \mathrm{MPa} \mathrm{m}^{1 / 2}\right)$, had never been achieved before in bainitic microstructures $[1,6$, 7], and compares well with maraging steels, which are at least ninety times more expensive.

In all cases the microstructure consisted of only two phases, retained austenite and bainitic ferrite, and as expected of adding $\mathrm{Si}$ in suffice quantities, it was essentially carbide free. Extensive transmission electron microscopy (TEM) failed to identify carbides in the microstructure, only a few small (20 nm wide and $175 \mathrm{~nm}$ long) cementite particles in the bainitic ferrite were found in samples transformed at $190{ }^{\circ} \mathrm{C}$ for 14 days [1]. Quite remarkably, the bainite plates formed at $200{ }^{\circ} \mathrm{C}$ have a width that is less than $50 \mathrm{~nm}$, see Table 2, with each plate separated by an even finer film of retained austenite. Very high strengths and hardness in excess of $600 \mathrm{HV}$ are achieved, primarily due to the extremely fine scale of the microstructure.

Steel makers and final users appreciated the mechanical properties and the impressive improvement in transformation kinetics, but still, the use of $\mathrm{Co}$ and $\mathrm{Al}$ as alloying elements in such quantities is unreasonable for economical and process viability reasons. Bearing this demand in mind and using the $\mathrm{Co}$ and $\mathrm{Co}+\mathrm{Al}$ alloys as reference, in terms of properties, microstructure and transformation kinetics, a new set of low-temperature bainitic steels have been designed. The premises were to obtain a nanostructured bainitic steel by transformation 
at low temperatures in industrially acceptable times and using inexpensive alloying additions. The following sections will detail the theoretical approach followed in the design of this NANOBAIN steel family.

\section{Theoretical approach. Relevant design parameters.}

This section highlights some of the most fundamental points of the diffusionless transformation theory used during the design process, which, from the point of view of the authors, represents the most plausible explanation given the considerable amount of reviewed experimental evidence [8-17]. Because they are inherent to the design process, some relevant factors determining the strength and ductility of these novel nanostructured alloys are also discussed.

The mechanism by which bainite grows places strict limits on the temperature range for transformation and on the maximum fraction of transformation that can ever be achieved. These criteria are embedded in the concept of the $T_{0}$ curve, which is the locus of points, on a temperature versus $\mathrm{C}$ concentration plot, where austenite and ferrite of the same chemical composition have the same free energy, taking into account for the stored energy, $G_{\mathrm{SB}}$, of the ferrite due to the displacive mechanism of transformation $\left(400 \mathrm{~J} \mathrm{~mol}^{-1}\right)[11,18,19]$. Thus, bainite is expected to occur below the $T_{0}^{\prime}$ temperature when $\Delta G^{\gamma \rightarrow \alpha}<-G_{\mathrm{SB}}$ and $\Delta G_{\mathrm{m}}<G_{\mathrm{N}}$. The first condition refers to the limits of growth. The second to the nucleation conditions, thus $\Delta G_{\mathrm{m}}$ is the maximum free energy change accompanying the nucleation under paraequilibrium conditions. The nucleation of bainite occurs via formation of a small volume with bcc structure, bounded by an array or dislocations. In this context, the critical driving force for nucleation of bainite $G_{\mathrm{N}}$ is defined as that which allows for propagation of the interface by dislocation movement against the lattice friction [11, 19-21]. $\Delta G^{\gamma \rightarrow \alpha}$ is the free energy change of the transformation of $\gamma$ into $\alpha$ without any change in chemical composition [19]. The temperature at which both conditions, nucleation and growth, are fulfilled is known as the bainite start temperature, $B_{\mathrm{S}}$, and it is illustrated schematically in Fig. 1. The diagram also includes an additional function, $G_{\mathrm{N}}^{\alpha^{\prime}}$, that represents the critical value of the free energy change $\Delta G^{\gamma \rightarrow \alpha}\left\{M_{\mathrm{S}}\right\}$ needed before the athermal, diffusionless nucleation and growth of 
martensite becomes possible [22]. Thus, martensite becomes possible when this condition, $\Delta G^{\gamma \rightarrow \alpha}\left\{M_{\mathrm{S}}\right\}<G_{\mathrm{N}}^{\alpha^{\prime}}$, is fulfilled at a given temperature, known as the martensite start temperature, $M_{\mathrm{S}}$.

Soon afterwards the diffusionless growth of a bainitic ferrite subunit is over, the excess of C is partitioned to the surrounding austenite. The process continues by successive nucleation of subunits until the $\mathrm{C}$ concentration of the residual austenite reaches the value at which the free energy of bainite becomes less than that of austenite of the same composition, i.e. the $T_{0}$ curve. This trend is known as an 'incomplete reaction phenomenon' because the transformation ends before the $\mathrm{C}$ concentration of austenite reaches the equilibrium value. It follows that the maximum amount of bainitic ferrite that can form in the absence of carbide precipitation is limited by the $T_{0}^{\prime}$ curve. Because bainitic ferrite is stronger than retained austenite [23], when seeking for high strength levels, it is important to maximise the fraction of bainitic ferrite. This can be done in three ways: by reducing the mean carbon concentration, by adjusting the $T_{0}$ curve to greater carbon concentrations using substitutional solutes, and by minimising the transformation temperature so the transformation can proceeds further as higher amounts of $\mathrm{C}$ in solution are allowed in austenite.

Attending to the description of the bainite transformation kinetics [24, 25], $\ln \left|\tau\left(\Delta G^{\gamma \rightarrow \alpha}\right)^{p} / T^{z}\right|=Q^{\prime} / R T+C$

where $\tau$ is the time, $T$ is the transformation temperature in Kelvin, and $p, z, Q^{\prime}$ and $C$ are constants, the rate at which bainite forms slows down dramatically as the transformation temperature is decreased. Therefore, although theoretically it appears that there is no limit to the lowest temperature at which bainite can be obtained, for practical purposes there is indeed a limitation. Acceleration of the bainite transformation might be achieved by making controlled additions of substitutional solutes to the steel, e.g. Co and Al, which increases the free energy change $\Delta G^{\gamma \rightarrow \alpha}$, NANOBAIN 3 and 4 in Table 1 and Table 2. But also, because bainite nucleates in austenite grain boundaries, further acceleration is possible by increasing the number density of nucleation sites i.e. refining the prior austenite grain size (PAGS) [3], which also leads to a reduction of the bainitic ferrite plate, $t$ [3].

Giving its displacive nature, bainite transformation causes shape deformation described as an invariant plane strain with a shear component $[8,11,19,26]$. The magnitude of which is so large that the product phase is constrained to be in the form of thin plate. Direct observations 
have shown that there is considerable plastic relaxation in the austenite adjacent to the bainitic plates [26, 27]. The defects generated in this process resist the advance of the $\gamma / \alpha$ interface, and its density increases as the transformation temperature decreases [28, 29]. Different experimental results have revealed not only the presence of a high dislocation density in ferrite and austenite but also multiple planar faults/twins in retained austenite, often with one dominant fault plane $[8,17,30]$.

In terms of the scale of the bainitic ferrite plates, it is known that stronger austenite and a larger driving force results in finer plates, the former because there is a large resistance to interface motion and the latter because an increased nucleation rate leads to microstructural refinement, and both magnitudes increase as the transformation temperature decreases [31, 32].

It is known that alloying the steel with about $1.5 \mathrm{wt} . \%$ of $\mathrm{Si}$ can in appropriate circumstances avoid cementite precipitation from the carbon-enriched austenite. As a cleavage and voidinitiating phase, cementite is best eliminated from the microstructure of strong steels. By adding $\mathrm{Si}$, austenite remains enriched in carbon after bainitic ferrite formation, thereby stabilizing it down to ambient temperature. The resulting microstructure then consists of plates of bainitic ferrite separated by carbon enriched regions of austenite [33].

As expected, the degree of complexity in understanding and characterising the microstructure increases as the nanoscale is approached. Detailed analysis of the microstructure reveals a plethora of unique microstructural and morphological peculiarities, which are a direct consequence of both the atomic mechanisms that rule bainitic transformation and the low temperatures at which transforms. For example, it has been shown how dislocations and twins, introduced during the displacive growth, are capable of trapping $\mathrm{C}$ atoms, preventing the decarburisation of supersaturated bainitic ferrite and altering carbide precipitation sequence during transformation [17, 34-36].

Retained austenite has two very distinguishable morphologies, as thin films between the plates of ferrite, and as blocks separating sheaves of bainite, groups of bainitic ferrite plates sharing a common crystallographic orientation. It has been proved that the level of $\mathrm{C}$ saturation is strongly related to its size, the thin films being much richer than blocks $[37,38]$. It has to be noted that enhancement of thin film morphology as opposed to blocky is attained by lowering the transformation temperature [39]. 
In terms of the most relevant relationships between microstructure and properties in carbidefree bainitic microstructures, it is known that the strength is mainly conferred by the amount and scale of the bainitic ferrite, harder phase [23]. The main operative strengthening mechanisms, in descending order of importance, are, bainitic ferrite plate thickness, dislocation density and excess of $\mathrm{C}$ in solid solution $[6,19]$.

Similarly, it can be considered that ductility is controlled by the volume fraction of retained austenite [40], also capable of enhancing ductility by its ability to transform to martensite through the transformation induced plasticity (TRIP) effect. In order to take full advantage of this effect, the mechanical stability of austenite, i.e. its capability to transform to martensite under strain, must be moderate. Such stability is mainly controlled by the chemical composition, and elements such as $\mathrm{C}, \mathrm{Mn}, \mathrm{Si}$ and $\mathrm{Al}$ [8, 41-43] significantly enhance mechanical stability, among them $\mathrm{C}$ is the element that exhibits the strongest influence. There are some other factors controlling austenite stability, e.g. the constriction exerted by the surrounding plates of ferrite, that may even halt martensitic transformation, the morphology of austenite, because thin films contain fewer potential nucleation sites for martensite and therefore require of higher driving force. For all those reasons, retained austenite thin films are mechanically more stable than those with blocky morphology [8, 44, 45].

So, when finally facing the design process, a limited set of parameters were selected as the most relevant to be considered.

-Simple alloy system. Undoubtedly, in order not to be restricted to niche applications, the new alloys must be cheap to produce. Therefore, elements such as Co because of the cost of raw material, and Al, incompatible with cleanliness requirements of ultra high strength steels, were ruled out during the design process, thus restricting the new alloys chemical compositions to the system $\mathrm{Fe}-\mathrm{C}-\mathrm{Si}-\mathrm{Mn}-\mathrm{Cr}$.

-Low transformation temperatures. Reducing the transformation temperature, has already been described as a way of : maximising bainitic ferrite fraction, enhance retained austenite thin film morphology as opposed to blocky (mechanically more unstable), decrease bainitic ferrite plates and increase dislocation density.

-Enhance transformation kinetics. This is an important industrial requirement, since the transformation must be achieved in a realistic time. So, during the design process, the chemical composition was tailored to obtain high values of the magnitude $\Delta G^{\gamma \rightarrow \alpha}[24,25]$. Besides this consideration, the new alloys must have sufficient hardenability. Because the 
intended heat treatment consisted in full austenitisation, at $T_{\gamma}>A \mathrm{c} 3$, followed by cooling to a temperature $T, M_{\mathrm{S}}<T<B_{\mathrm{S}}$, where the component is held isothermally until the end of the bainitic transformation, it is important that the designed steels have suffice hardenability to avoid, at all instances, ferrite/pearlite transformation during cooling. Not only for the possible damage to the final mechanical properties, but also because the whole design process is based on the assumption that austenite, previous to bainite transformation, has the bulk chemical composition, and if ferrite/pearlite forms during cooling, the austenite would have a different composition from the bulk, and the whole design process is jeopardised. In this sense especial efforts were made in order to define an industrially acceptable critical cooling rate, and it was concluded that the adapted steel grade would be designed not to form ferrite/pearlite for any cooling rate faster than $1.5 \mathrm{Ks}^{-1}$.

As already described, thermodynamics underlies all the necessary calculations for the design of the new alloys, and, for this purpose, MT-DATA in combination with the SGSOL-SGTE Solution database were used [46]. From Figs. 2 to 4 a set of calculations, similar to those just described, are illustrated.

In Fig. 2, calculations of the variation of the $B_{\mathrm{S}}$ and $M_{\mathrm{S}}$ temperatures as a function of chemical composition are summarised. It is evident that the most efficient way to achieve low $B_{\mathrm{S}}$ and $M_{\mathrm{S}}$ temperatures is by means of increasing quantities of $\mathrm{C}$ and, to a lesser extent, solutes such as $\mathrm{Mn}$ and $\mathrm{Cr}$.

Calculations of the driving force for diffusionless transformation, $\Delta G^{\gamma \rightarrow \alpha}$, were used as an indicator of the transformation rate [24, 25], and examples of such calculations at $200{ }^{\circ} \mathrm{C}$ are shown in Fig. 3. It is clear that as the $\mathrm{C}$ content is increased, the magnitude of the free energy change decreases drastically, Fig. 3a, in comparison with the more gentle decrease detected when adding increasing quantities of $\mathrm{Mn}, \mathrm{Cr}$ and Mo, Fig. 3b. The acceleration in the transformation kinetics previously achieved using $\mathrm{Co}$ and $\mathrm{Al}$ has to be compensated by reducing the quantities of $\mathrm{Mn}$ and $\mathrm{Cr}$, and when possible the $\mathrm{C}$ content as well.

Following the procedures described in Ref. [24] and Ref. [25] for the calculation of the noses corresponding to the diffusional and diffusionless transformation curves, and, in combination with $B_{\mathrm{S}}$ and $M_{\mathrm{S}}$ calculations, it is possible to build theoretical TTT diagrams of the type shown in Fig. 4. Also plotted is the critical cooling rate curve as an indication of hardenability. The curve should really be plotted on CCT diagrams, where the transformation 
curves would be displaced to longer times. As expected from experience, increasing quantities of $\mathrm{Mn}$ greatly retard both types of transformation, diffusionless and diffusion controlled, therefore its use should be moderate, see results in Fig. 4 for the $1 \mathrm{C}-1.5 \mathrm{Si}-1 \mathrm{Cr}-\mathrm{XMn}$ wt.\% system.

\section{Material selection}

Based on the descriptions and calculations described above, a group of nine alloys was proposed, see Table 3. It is clear that in order to achieve the required low $B_{\mathrm{S}}$ and $M_{\mathrm{S}}$ temperatures, the use of high $\mathrm{C}$ concentrations and, to a lesser extent, solutes such as $\mathrm{Mn}$ and $\mathrm{Cr}$ is necessary, see Fig. 5a. Because the use of high levels of $\mathrm{C}$ slows down the transformation kinetics, a judicious use of $\mathrm{Mn}$ and $\mathrm{Cr}$ was made in order to keep the driving force $\Delta G^{\gamma \rightarrow \alpha}$ between those of the references steels, NANOBAIN 4 and NANOBAIN 2. At the same time, a reduction in the average $\mathrm{C}$ content down to 0.8 or $0.6 \mathrm{wt} . \%$ was introduced in

a few of the new steels, Table 3. The transformation temperatures thus increased, $B_{\mathrm{S}}<380{ }^{\circ} \mathrm{C}$ and $M_{\mathrm{S}}<200{ }^{\circ} \mathrm{C}$ in Fig. 5a, but the consequent increase in the magnitude of the corresponding driving force places those alloys to a level comparable to NANOBAIN 4, the fastest in their class to date, Fig. 5b. All these effects are also summarised in the theoretical TTT diagrams in Fig. 6. Using the critical cooling rate curve as an indication, the diagrams also helped to estimate the hardenability of the designed alloys, and the results suggest that the formation of proeutectoid ferrite and pearlite can be avoided during cooling from $T_{\gamma}$ to the isothermal heat treatment temperature.

All the alloys in Table 3, without exception, contain sufficient Si (at least 1.5 wt.\%) to suppress the precipitation of cementite from austenite [33]. It is also known that $\mathrm{Si}$ is a strong austenite solid solution hardener [47, 48], therefore the use of this element in higher quantities, in principle, is a way to ensure that the bainite growth results in even finer plates. In a similar manner Mo was also included, but in much lower quantities among other reasons for its price and lower hardening capacity. Thus, in some cases, Si additions were increased up to $2.5 \mathrm{wt} . \%$ and for Mo up to $0.1 \mathrm{wt} \%$, see Table 3.

As anticipated, another way of accelerating bainitic transformation is by reducing the PAGS. Experimentally there are two approaches that can be used, first, to keep the austenitisation temperature as low as possible and second, limiting PAGS growth by a pinning effect exerted 
by stable precipitates, and $\mathrm{Nb}$ is well known to form stable carbonitrides that inhibit grain boundary growth [49], thus 0.03 wt.\% Nb was used in some of the alloys, see Table 3.

\section{Experimental verification}

The present section provides an overview of the experimental results obtained for the selected steel grades that come to confirm the validity of the design process. Most of those results are being published separately in much greater detail.

\subsection{Experimental procedure}

The selected laboratory steel grades were induction-melted under vacuum, cast into rectangular ingots of approximately $20-35 \mathrm{~kg}$, and finally hot forged into $40-50 \mathrm{~mm}$ diameter bars at a temperature between $1200-1250{ }^{\circ} \mathrm{C}$.

A high resolution dilatometer, model Bahr 805-D, was used to determine the critical transformation temperatures and to perform all the heat treatments, using cylindrical samples $4 \mathrm{~mm}$ in diameter and $10 \mathrm{~mm}$ length.

To reveal the microstructure, metallographic samples were cut, ground and polished following standard procedures. A $2 \%$ Nital etching solution was used to reveal bainitic microstructure, and its observation was carried out on a JEOL J8M-6500 field emission gun scanning electron microscope (FEG-SEM) operating at $10 \mathrm{kV}$. High magnification micrographs were used to determine the bainitic ferrite plate thickness $t$, by measuring the mean lineal intercept $\bar{L}_{\mathrm{T}}=\pi t / 2$ in a direction normal to the plate length [50].

Quantitative X-ray diffraction analysis was used to determine the fraction of bainitic ferrite $\left(V_{\mathrm{b}}\right)$ and retained austenite. For this purpose, samples were ground and finally polished using colloidal silica suspension. They were then step-scanned in a Siemens D5000 X-ray

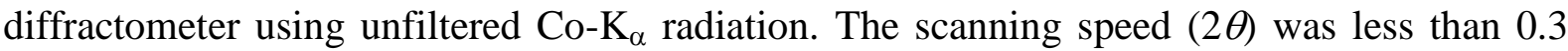
${ }^{\circ} \mathrm{min}^{-1}$. The machine was operated at $40 \mathrm{kV}$ and $30 \mathrm{~mA}$. The volume fraction of the phases were calculated using the integrated intensities of the (111), (200), (220) and (311) austenite peaks and the (110), (200) and (211) peaks of ferrite [38].

Tensile tests were performed on cylindrical specimens $5 \mathrm{~mm}$ diameter with $12 \mathrm{~mm}$ gauge length, and were assisted by an extensometer. The reported results correspond to an average of at least four tests. 
Hardness was measured as $H V$ and the presented results correspond to an average of at least 3 values.

\subsection{Experimental results}

The $M$ s temperatures of $1 \mathrm{C} \& 0.8 \mathrm{C}$ alloys were found to be in the range $123-165^{\circ} \mathrm{C}$, while for the $0.6 \mathrm{C}$ family, the anticipated increase in the $M_{\mathrm{S}}$ was up to $200-240{ }^{\circ} \mathrm{C}$. Austenitisation temperatures were selected in order to avoid exaggerated austenite grain growth but at the same time to ensure complete austenitisation, thus $950{ }^{\circ} \mathrm{C}$ and $890{ }^{\circ} \mathrm{C}$ were chosen for the $1 \mathrm{C}$ \& $0.8 \mathrm{C}$ and the $0.6 \mathrm{C}$ alloys systems, respectively. The isothermal heat treatments for the bainitic transformation were limited to the range $200-350{ }^{\circ} \mathrm{C}$ and $250-350{ }^{\circ} \mathrm{C}$ for the $1 \mathrm{C} \&$ $0.8 \mathrm{C}$ and the $0.6 \mathrm{C}$ alloys respectively.

A summary of the transformation times thus obtained is presented in Fig. 7. It is clear that all the alloys have suffice hardenability to avoid ferrite/pearlite transformation at cooling rates higher than $1.5 \mathrm{Ks}^{-1}$, value used during the design process as an industrially acceptable rate. Figure 7 only presents the time to finish the transformation at the lowest temperatures, i.e. the slowest transformation, and yet the results reveal an important decrease when compared with the fastest of the reference alloys, NANOBAIN $3 \& 4$ in Table 2. For example, in the case of the $1 \mathrm{C}$ alloys the fastest and the slowest need about $30-40 \mathrm{~h}$ and $55 \mathrm{~h}$ at $200{ }^{\circ} \mathrm{C}$ to end the transformation, representing an important acceleration of the transformation when compared with the $72 \mathrm{~h}$ needed in the case of NANOBAIN $3 \& 4$, Table 2.

$H V$ results also reveal that bainite in the $1 \mathrm{C} \& 0.8 \mathrm{C}$ is harder than that in the reference alloys, Fig. 7 and Table 2, values were always in excess of $700 \mathrm{HV}$. It is interesting to note that even the $0.6 \mathrm{C}$ alloys exhibited similar $H V$ values to the reference alloys, with higher $\mathrm{C}$ content.

Without exception, in all the isothermal heat treatments the microstructure consisted of a mixture of two phases, see Fig. 8, bainitic ferrite $(\alpha)$, darker and elongated features, and carbon enriched regions of austenite $(\gamma)$, lighter phase among the plates of bainite. Results from a detailed microstructural analysis are summarised in Fig. 9, and it is clear that the microstructure is mainly composed of bainitic ferrite, almost $67-88 \%$ of volume fraction, $V_{\mathrm{b}}$, the remaining being retained austenite. Figure 9 comes to confirm that bainitic ferrite plate, measured in micrographs of the type showed in Fig. 8, is within the nano-range. Two sets of data can be identified, first the 0.6C family with plate thicknesses ranging from 43-65 nm, being the thinnest those corresponding to stronger austenite, i.e. alloys with Mo and $\mathrm{Cr}$. The 
other set, 1C \& 0.8C alloys, has plate thicknesses which are almost half of that reported for the $0.6 \mathrm{C}$ alloys, $28-39 \mathrm{~nm}$. When the same results of the reference alloys in Table 2 are compared with those in Fig. 9, it is possible to appreciate an extra refinement of the microstructure.

In carbide-free bainitic microstructures, strength is mainly controlled by the amount and scale of the bainitic ferrite, harder phase. It is not strange then, that the high fractions of such fine bainitic ferrite plates, Fig. 9, lead to UTS values always in excess of $2 \mathrm{GPa}$, and $Y S$ that range, from 1.5 to $1.8 \mathrm{GPa}$, for the $0.6 \mathrm{C}$ and the $1 \mathrm{C} \& 0.8 \mathrm{C}$ alloys respectively, Fig. 10 . What is more, in spite of such high strength levels there is also a considerable level of ductility, in the case of $1 \mathrm{CSi}, 0.6 \mathrm{CNb}$ and $0.6 \mathrm{CMo}$ about $20 \%$ of total elongation is achieved, Fig. 10. The study of the ductility is invariably linked to the evolution of the TRIP effect, i.e., the mechanical stability of retained austenite $[43,51,52]$. Other microstructural parameters, such as morphology-size-distribution and strength of both the ferritic matrix and the retained austenite itself, are the subject of further research in relation with the role they play in the TRIP effect and work-hardening response of these microstructures.

\section{Conclusions}

Although the mechanism by which bainite grows places strict limits on the temperature range for transformation, if it is kept as low as possible, the scale of such microstructure can be tailored to the nanoscale. In this work is shown the theoretical approach to design steels, which by phase transformation of austenite into bainite at low temperatures $\left(200-280{ }^{\circ} \mathrm{C}\right)$, gave rise to a microstructure consisting of an interwoven mixture of bainitic ferrite plates and carbon enriched austenite, both just a few tens of nm in thickness.

The approach is based on the thermodynamic description of the diffusionless nature of bainite, the transformation kinetic model that uses the free energy change of the transformation and finally, some relevant microstructure/properties relationships. During the design process there were also some industrial constraints that needed to be considered; enough hardenability, faster transformation kinetics and simpler and cheaper chemical compositions.

Finally a set of nine alloys were selected and prepared at laboratory scale. The microstructural and mechanical characterization of the bainitic microstructures obtained by isothermal 
transformation at different temperatures, come to confirm and to validate the followed theoretical approach for the design of the latest generation of NANOBAIN steels.

The authors gratefully acknowledge the support of the European Research Fund for Coal and Steel and the Spanish Ministerio de Economia y Competitividad Plan Nacional de I+D+I (2008-2011) for funding this research under the contracts RFSR-CT-2008-00022, and MAT2010 - 15330 respectively.

The authors would like to acknowledge the valuable scientific and industrial insights gained from Dr. M. Kuntz. C. Garcia-Mateo is particularly grateful to L.M. Aguado for engaging in this adventure. 


\section{References}

[1] F.G. Caballero, H.K.D.H. Bhadeshia, K.J.A. Mawella, D.G. Jones, P. Brown: Mater. Sci. Technol. 18 (2002) 279.

[2] C. Garcia-Mateo, F. G. Caballero, H.K.D.H. Bhadeshia: ISIJ Int. 43 (2003) 1238.

[3] C. Garcia-Mateo, F.G. Caballero, H.K.D.H. Bhadeshia: ISIJ Int. 43 (2003) 1821.

[4] H.I. Aaronson, H.A. Domian, G.M. Pound: Trans. Metall. AIME. 236 (1966) 781.

[5] T. Sourmail, V. Smanio: Metall. Mater. Trans. A 44 (2013) 1975.

[6] C. Garcia-Mateo, F.G. Caballero: ISIJ Int. 45 (2005) 1736.

[7] C. Garcia-Mateo, F.G. Caballero: Int. J. Mater. Res. 98 (2007) 137.

[8] H.K.D.H. Bhadeshia, D.V. Edmonds: Metall. Trans. A 10 (1979) 895.

[9] B.P.J. Sandvik: Metall. Trans. A 13 (1982) 777.

[10] H.K.D.H. Bhadeshia, D.V. Edmonds: Acta Metall. 28 (1980) 1265.

[11] H.K.D.H. Bhadeshia: Acta Metall. 29 (1981) 1117.

[12] I. Stark, G.D.W. Smith, H.K.D.H. Bhadeshia: Metall. Trans. A 21 (1990) 837.

[13] K. Tsuzaki, A. Kodai, T. Maki: Metall. Mater. Trans. A 25 (1994) 2009.

[14] B. Josefsson, H.O. Andren: Mater. Sci. Technol. 7 (1991) 849.

[15] F.G. Caballero, C. Garcia-Mateo, M.J. Santofimia, M.K. Miller, C. García de Andrés: Acta Mater. 57 (2009) 8.

[16] F.G. Caballero, M. K. Miller, C. Garcia-Mateo: Acta Mater. 58 (2010) 2338.

[17] F.G. Caballero, H.W.Yen, M.K. Miller, J.R. Yang, J. Cornide, C. Garcia-Mateo: Acta Mater. 59 (2011) 6117.

[18] H.K.D.H. Bhadeshia, A.R. Waugh: Acta Metall. 30 (1982) 775.

[19] H.K.D.H. Bhadeshia: Bainite in Steels. Transformations, Microstructure and Properties, Institute of Materials, Minerals and Mining, London, (2001).

[20] C. Garcia-Mateo, H.K.D.H. Bhadeshia: Mater. Sci. Eng. A 378 (2004) 289.

[21] G.B. Olson, M. Cohen: Metall. Trans. A 7 (1976) 1897.

[22] G. Ghosh, G.B. Olson: Acta Metall. Mater. 42 (1994) 3361.

[23] F. Hu, K. Wu: Adv. Mater. Res. 146-147 (2011) 1843.

[24] H.K.D.H. Bhadeshia: Met. Sci. 16 (1982) 159.

[25] J.L. Lee, H.K.D.H. Bhadeshia: Mater. Sci. Eng. A 171 (1993) 223. 
[26] M.J. Peet, H.K.D.H. Bhadeshia: Metall. Mater. Trans. A 42 (2011) 3344.

[27] E. Swallow, H.K.D.H. Bhadeshia: Mater. Sci. Technol. 12 (1996) 121.

[28] M.K. Fondekar, A.M. Rao, A.K. Mallik: Metall. Trans. A 1 (1970) 885.

[29] M. Takahashi, H.K.D.H. Bhadeshia: Mater. Sci. Technol. 6 (1990) 592.

[30] M. Nemoto: High Voltage Electron Microscopy, Academic Press, New York NY, (1974).

[31] S.B. Singh, H.K.D.H. Bhadeshia: Mater. Sci. Eng. A 245 (1998) 72.

[32] J. Cornide, C. Garcia-Mateo, C. Capdevila, F.G. Caballero: J. Alloys Compd. 577, Supplement 1 (2013) S43.

[33] E. Kozeschnik, H.K.D.H. Bhadeshia: Mater. Sci. Technol. 24 (2008) 343.

[34] F.G. Caballero, M. K. Miller, S. S. Babu, C. Garcia-Mateo: Acta Mater. 55 (2007) 381.

[35] F.G. Caballero, M.K. Miller, C. Garcia-Mateo, C. Capdevila, S.S. Babu: Acta Mater. 56 (2008) 188.

[36] F.G. Caballero, M.K. Miller, C. Garcia-Mateo: Metall. Mater. Trans. A 42 (2011) 3660.

[37] H.J. Stone, M.J. Peet, H.K.D.H. Bhadeshia, P. J. Withers, S.S. Babu, E.D. Specht: Proc. R. Soc. A 464 (2008) 1009.

[38] C. Garcia-Mateo, F.G. Caballero, M.K. Miller, J.A. Jimenez: J. Mater. Sci. 47 (2012) 1004.

[39] H.K.D.H. Bhadeshia, D. V. Edmonds: Met. Sci. 17 (1983) 411.

[40] B.P.J. Sandvik, H. P. Navalainen: Met. Technol. 8 (1981) 213.

[41] P.J. Jacques, E. Girault, A. Mertens, B. Verlinden, J. Van Humbeeck, F. Delannay: ISIJ Int. 41 (2001) 1068.

[42] K. Nohara, Y. Ono, N. Ohashi: Tetsu To Hagane-J. ISIJ. 63 (1977) 212.

[43] M.Y. Sherif, C. Garcia-Mateo, T. Sourmail, H.K.D.H. Bhadeshia: Mater. Sci. Technol. 20 (2004) 319.

[44] C.A.N. Lanzillotto, F.B. Pickering: Met. Sci. 16 (1982) 371.

[45] N.K. Balliger, T. Gladman: Met. Sci. 15 (1981) 95.

[46] NPL, MTDATA, Software, National Physical Laboratory, Teddington, U.K., 2006.

[47] K.J. Irvine, T. Gladman, F.B. Pickerin: J. Iron Steel Inst. 207 (1969) 1017.

[48] C.H. Young, H.K.D.H. Bhadeshia: Mater. Sci. Technol. 10 (1994) 209.

[49] T. Gladman: The physical metallurgy of microalloyed steels, Institute of Materials, London, (1997). 
[50] L.C. Chang, H.K.D.H. Bhadeshia: Mater. Sci. Technol. 11 (1995) 874.

[51] C. Garcia-Mateo, F.G. Caballero, J. Chao, C. Capdevila, C. Garcia de Andres: J. Mater. Sci. 44 (2009) 4617.

[52] F.G. Caballero, C. García-Mateo, J. Chao, M.J. Santofimia, C. Capdevila, C.G. De Andrés: ISIJ Int. 48 (2008) 1256. 


\section{Correspondence Address :}

Dr. Carlos Garcia-Mateo.

National Center for Metallurgical Research (CENIM-CSIC).

Avda. Gregorio del Amo 8. Madrid E-28040.

Spain.

Fax: +34915347425

cgm@cenim.csic.es.

\section{List of tables and figures captions}

Table 1. Chemical compositions of the first generation of NANOBAIN steels, wt.\%, and experimental $M_{\mathrm{S}}$ and $B_{\mathrm{S}}$ temperatures in ${ }^{\circ} \mathrm{C}$.

Table 2. Quantitative experimental data of the first generation of NANOBAIN steels. $V_{\mathrm{b}}$ is the volume fraction of bainitic ferrite, the remainder of the microstructure being retained austenite. $T$ stands for the isothermal transformation temperature, and Time to that needed to finish the transformation, $t$ is the stereologically corrected value of the bainitic ferrite plate thickness [1-3].

Table 3. Chemical composition of proposed alloys (wt.\%).

Figure 1. Thermodynamics based graphical solution of $B_{\mathrm{S}}$ and $M_{\mathrm{S}}$ temperatures.

Figure 2. Calculated transformation temperatures $M_{\mathrm{S}}$ and $B_{\mathrm{S}}$ as a function of chemical composition in different systems: (a) XC-1.5Si-1.5Mn-2.25Cr wt.\%, (b) $1 \mathrm{C}-1.5 \mathrm{Si}-0.5 \mathrm{Mn}-$ XCr wt.\% and (c) $1 \mathrm{C}-1.5 \mathrm{Si}-\mathrm{XMn}$ wt.\%.

Figure 3. Calculated driving force for diffusionless transformation in alloy systems of the type: (a) $1 \mathrm{C}-1.5 \mathrm{Si}-\mathrm{X}$ wt.\% where $\mathrm{X}$ represents $\mathrm{Mn}, \mathrm{Cr}$ or $\mathrm{Mo}$ and (b) $\mathrm{XC}-1.5 \mathrm{Si}-1.5 \mathrm{Mn}$ wt.\% and $\mathrm{XC}-1.5 \mathrm{Si}-1.5 \mathrm{Mn}-2.25 \mathrm{Cr}$ wt.\%.

Figure 4. Example of the TTT diagram calculations as a function of the chemical composition.

Figure 5. Theoretical calculations for the selected alloys in comparison with the reference alloys: (a) $B_{\mathrm{S}}$ and $M_{\mathrm{S}}$ critical transformation temperatures and (b) driving force for diffusionless transformation. 
Figure 6. Theoretical TTT diagrams for the proposed alloys as compared with the reference ones, also represented is the critical cooling rate in order to avoid formation of ferrite/pearlite prior to bainite transformation: (a) for the $1 \mathrm{C} \& 0.8 \mathrm{C}$ family and (b) for the $0.6 \mathrm{C}$ alloys

Figure 7. Time to end bainitic transformation at the lowest tested temperature, indicated at the top of the graph, and their corresponding $H V$. Hardness values represents the mean value of at least three measurements, with a typical variation of only $\pm 10 \mathrm{HV}$.

Figure 8. Example of the nanoscale microstructure obtained in 1CMo alloy after transformation at $250{ }^{\circ} \mathrm{C}$.

Figure 9. Fraction of bainitic ferrite, $V_{\mathrm{b}}$, and measured bainitic ferrite plate thickness, $t$.

Figure 10. Results from tensile test experiments. 


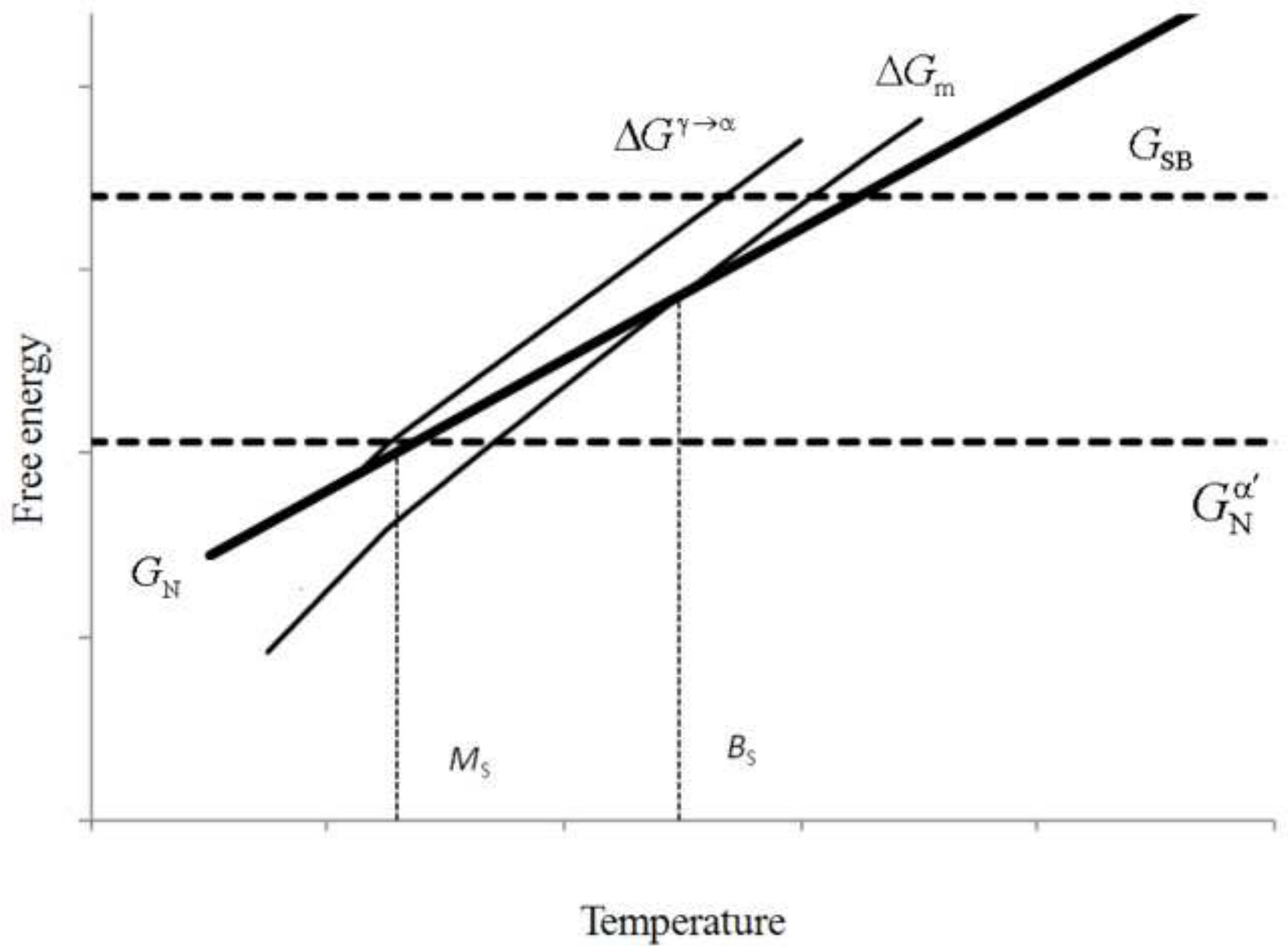

Figure 1. Thermodynamics based graphical solution of BS and MS temperatures. 


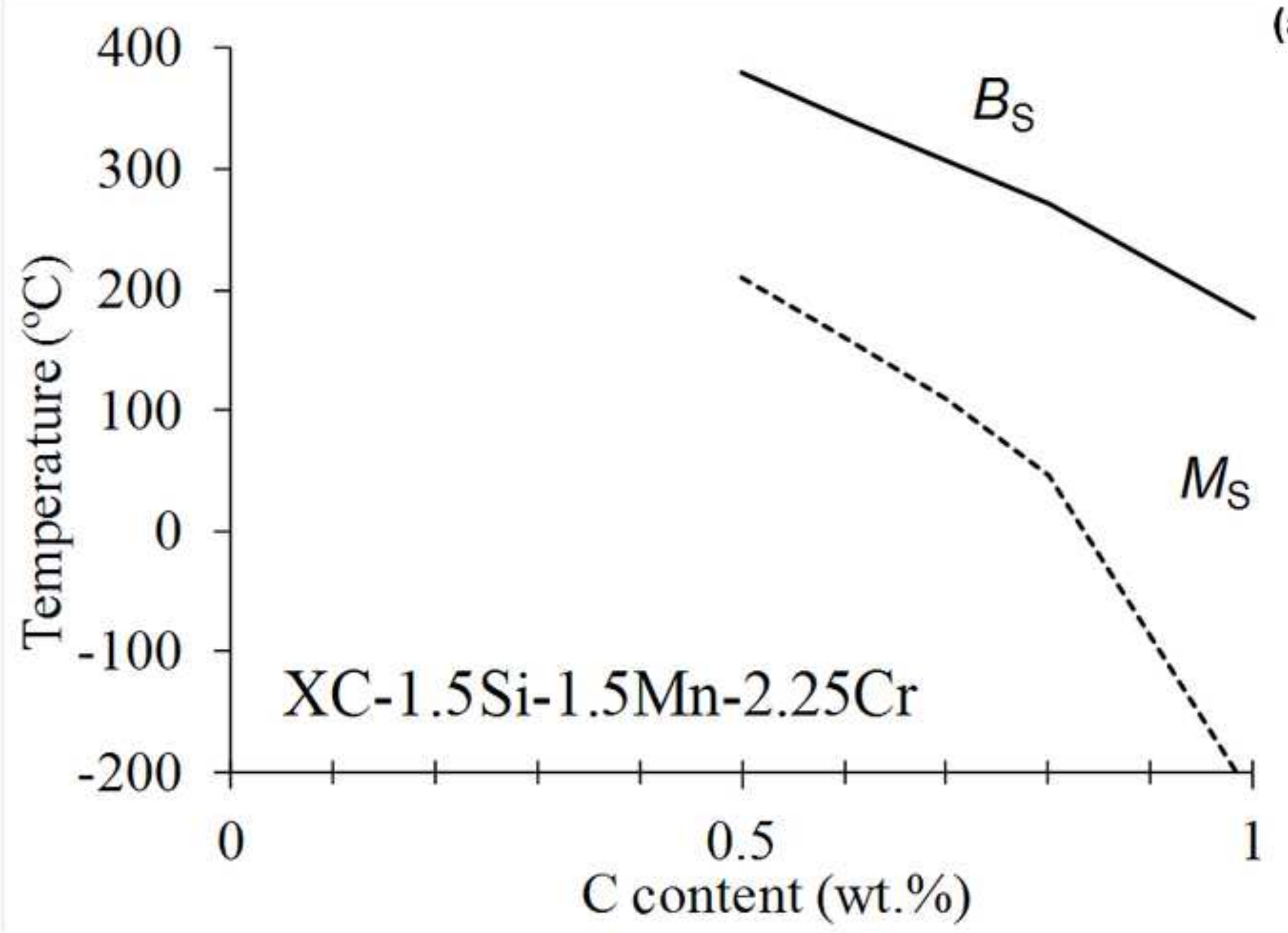

(a)

Figure 2. Calculated transformation temperatures MS and BS as a function of chemical composition in different systems of the type Fe-C-Si-Mn-Cr. 


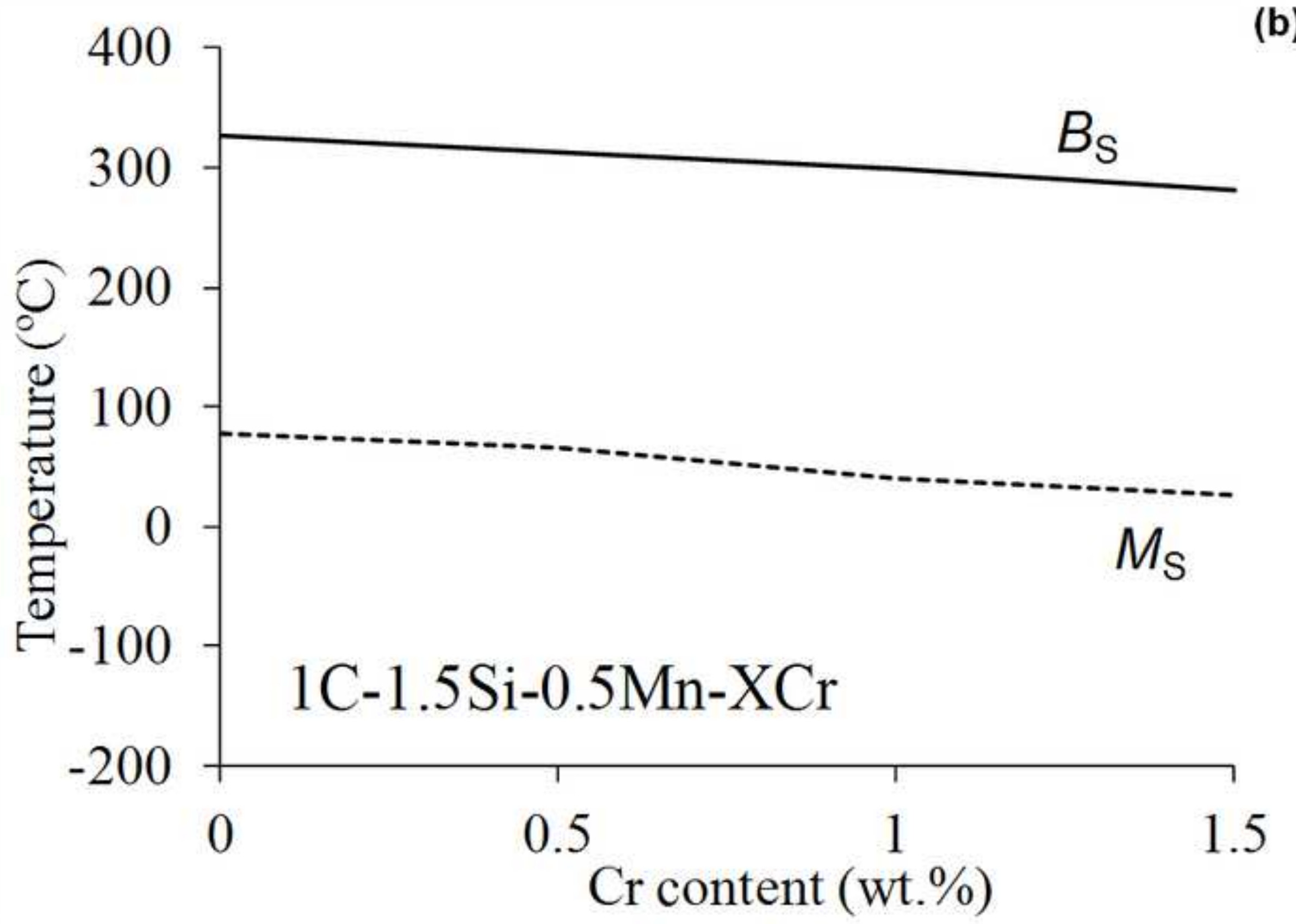

Figure 2. Calculated transformation temperatures MS and BS as a function of chemical composition in different systems of the type Fe-C-Si-Mn-Cr. 


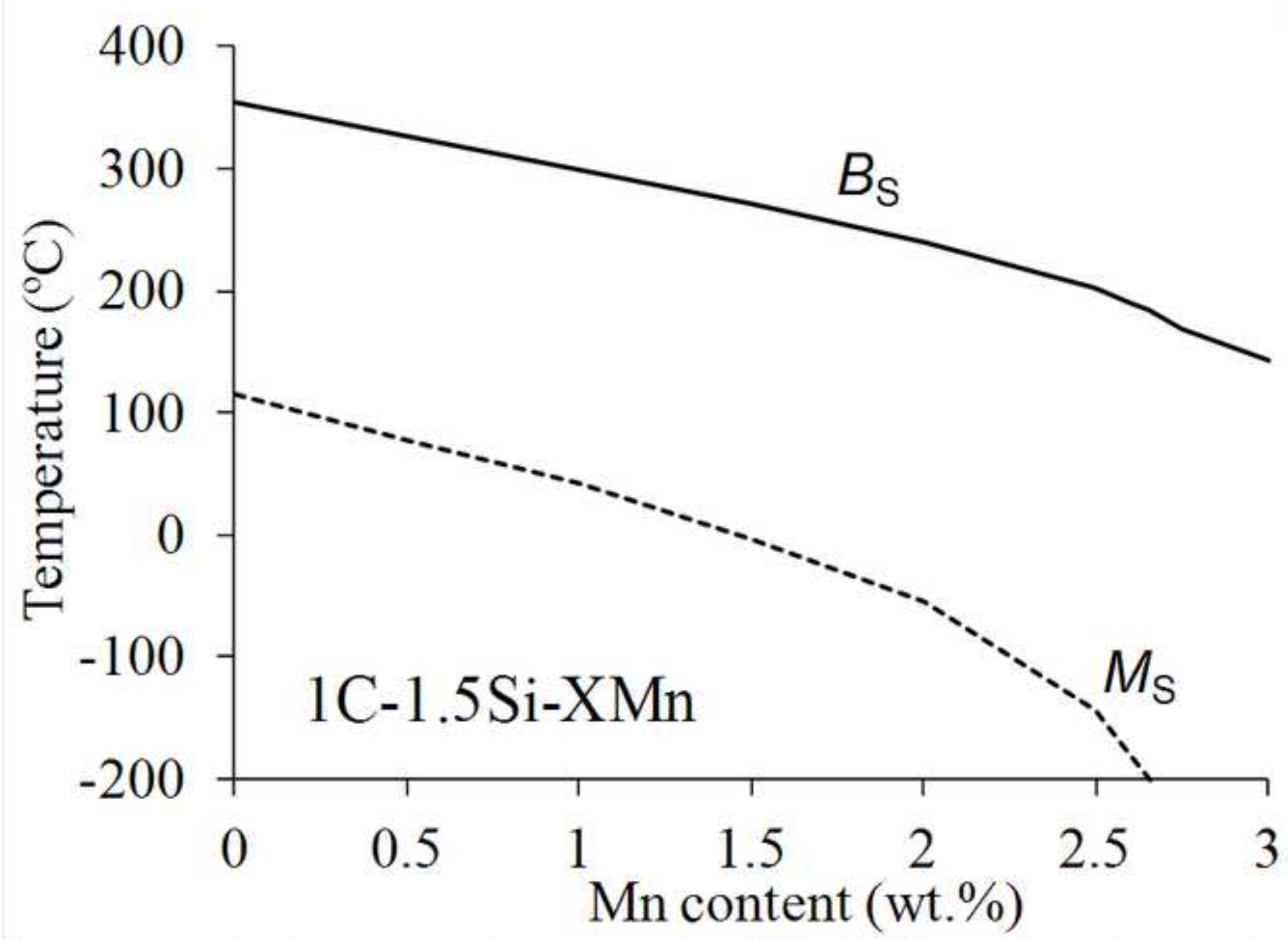

(c)

Figure 2. Calculated transformation temperatures MS and BS as a function of chemical composition in different systems of the type Fe-C-Si-Mn-Cr. 


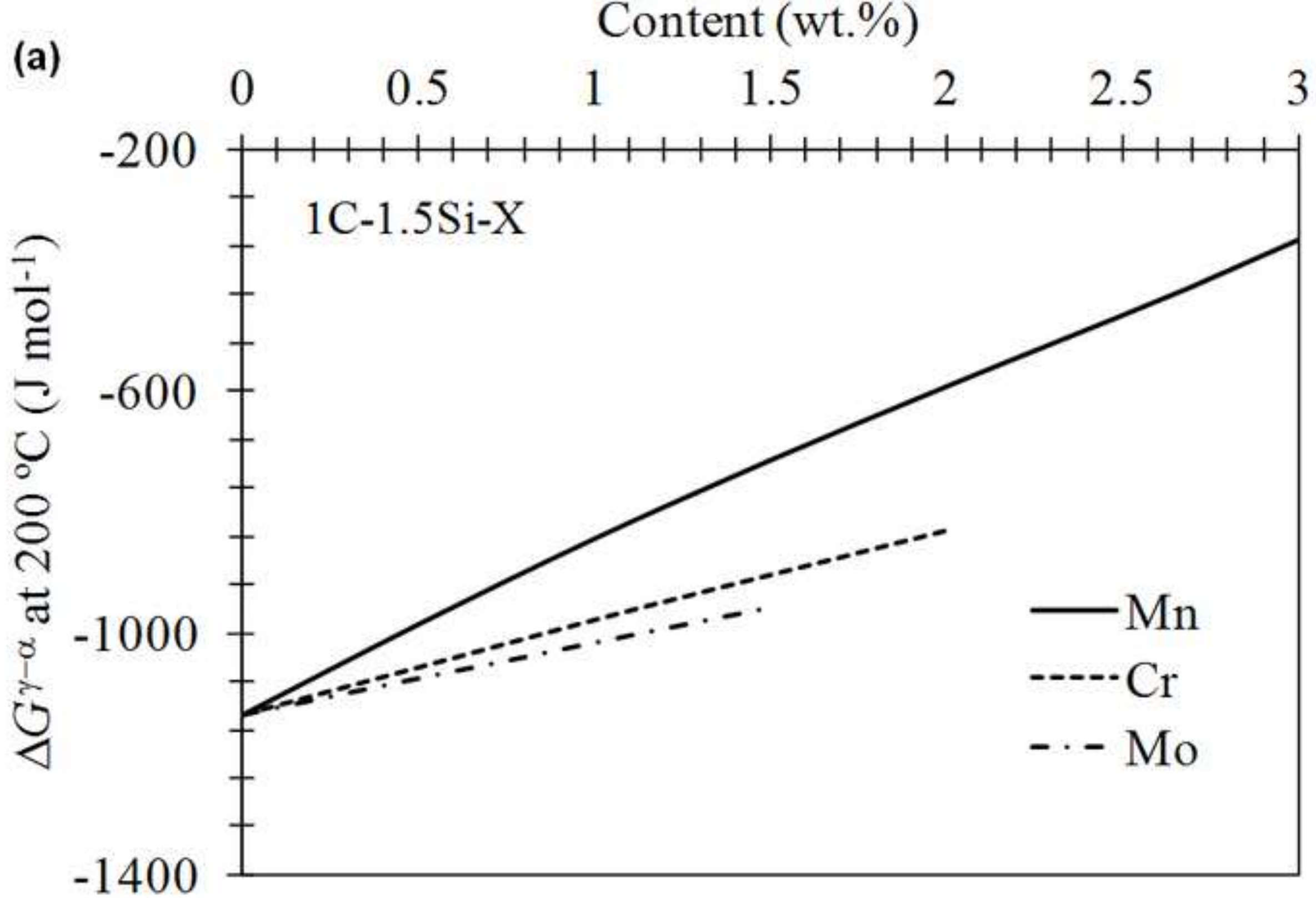

Figure 3. Calculated driving force for diffusionless transformation in different alloys systems....... 
(b)

C content (wt.\%)

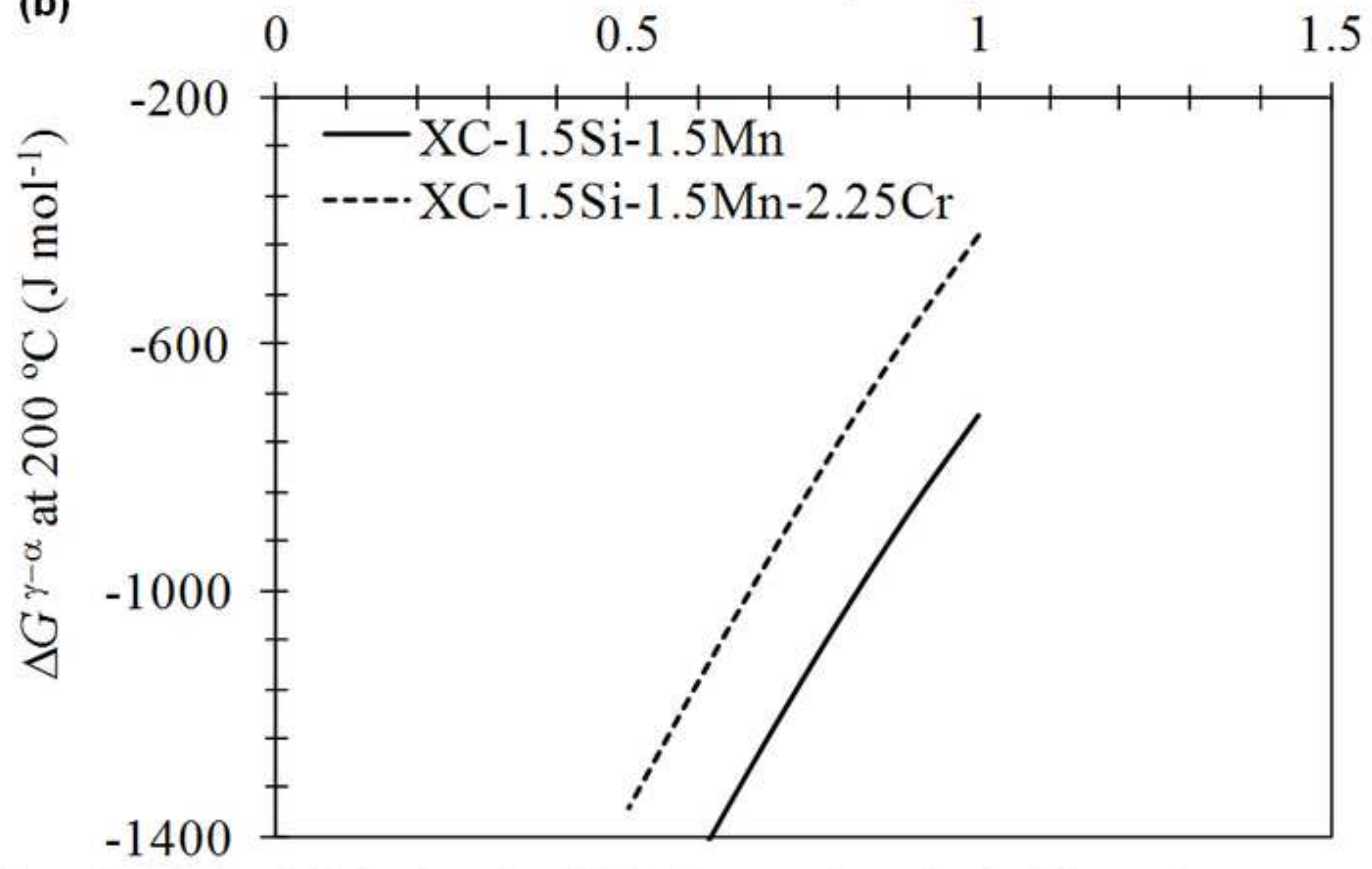

Figure 3. Calculated driving force for diffusionless transformation in different alloys systems.......... 


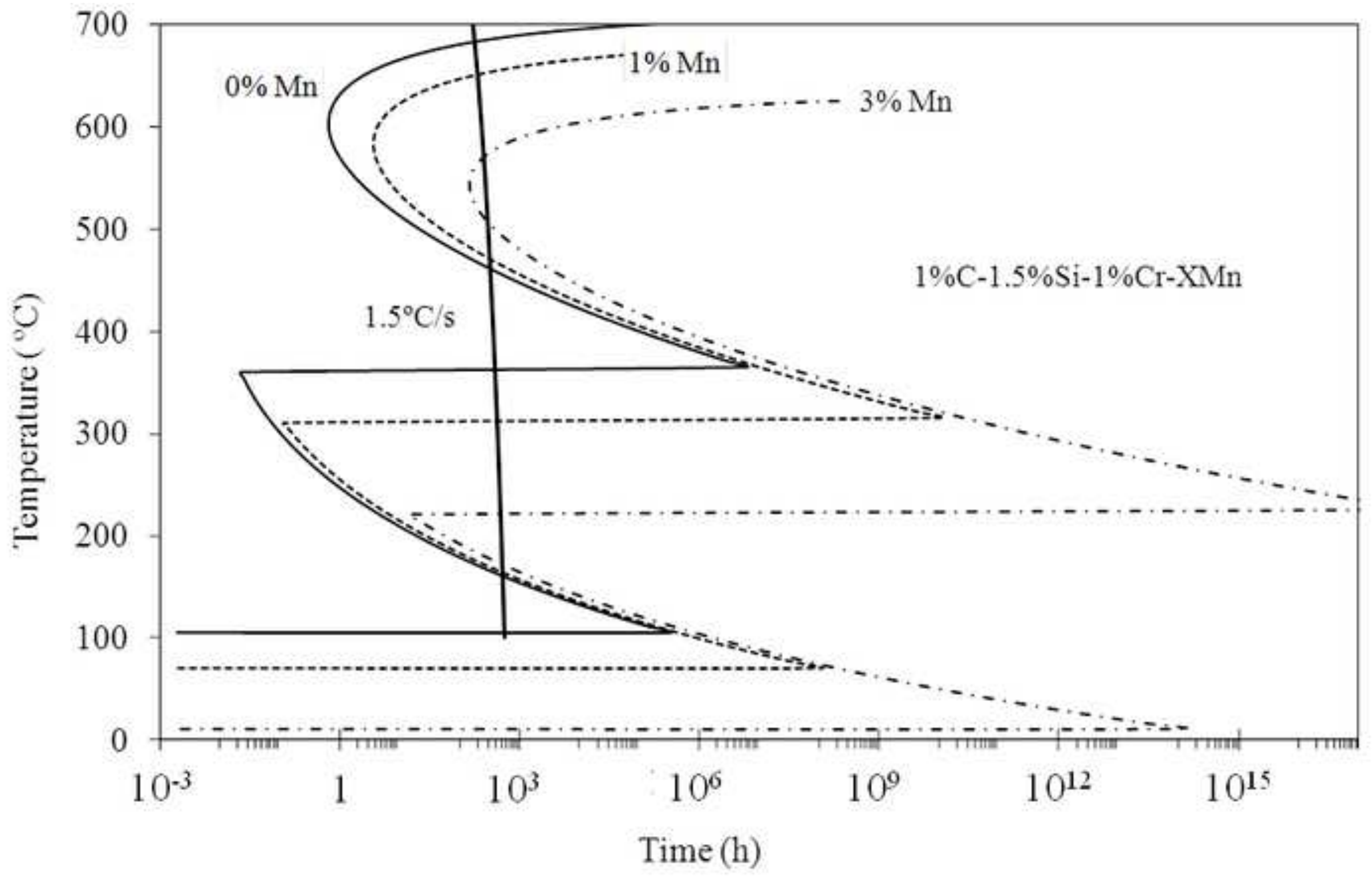

Figure 4. Example of the TTT diagrams calculations as a function of the chemical composition. 


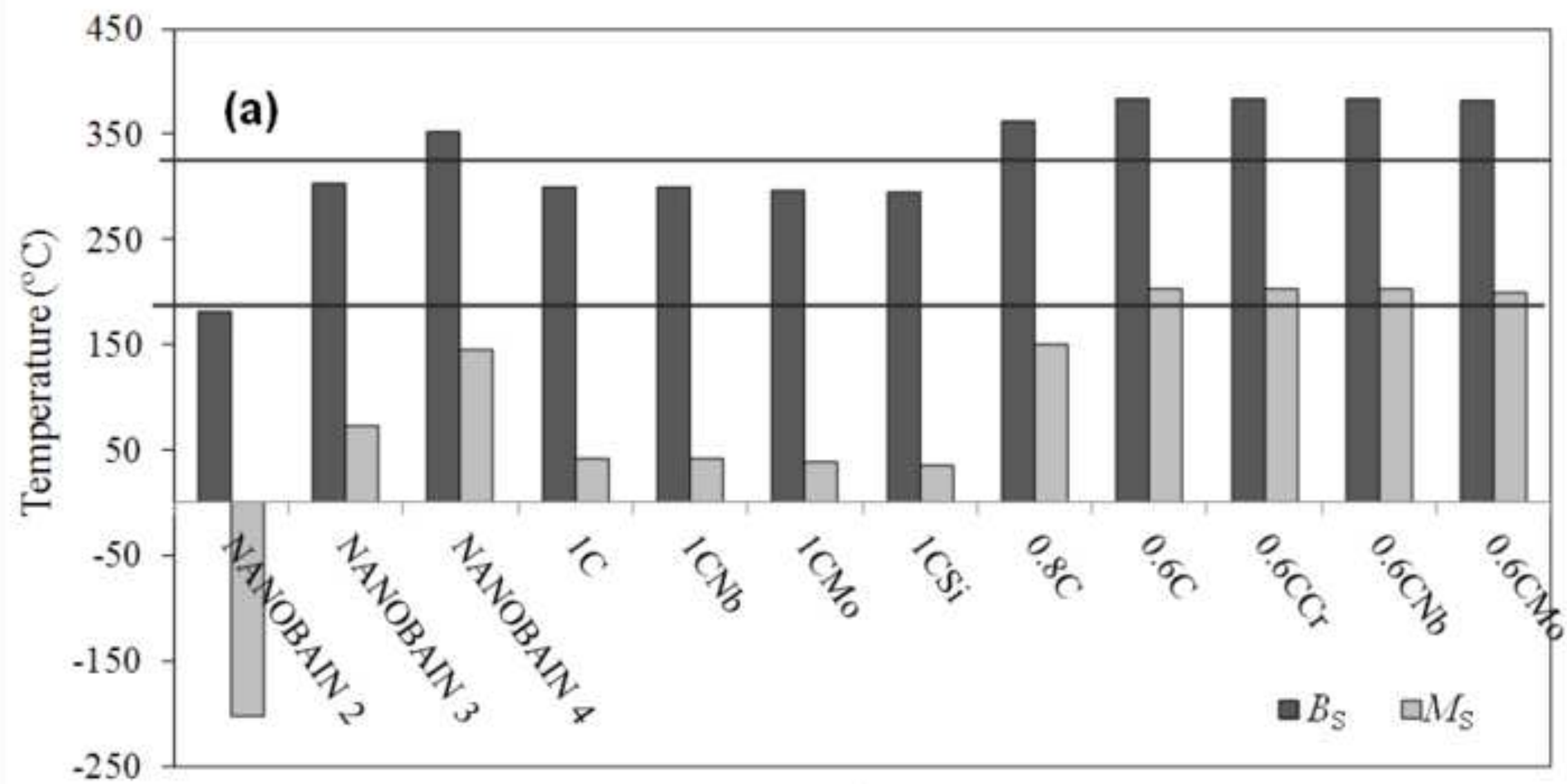

Alloys

Figure 5. Theoretical calculations for the selected alloys in comparison with the reference alloys: (a) BS and MS critical transformation temperatures and (b) driving force for diffusionless transformation 


\section{Temperature $\left({ }^{\circ} \mathrm{C}\right)$}

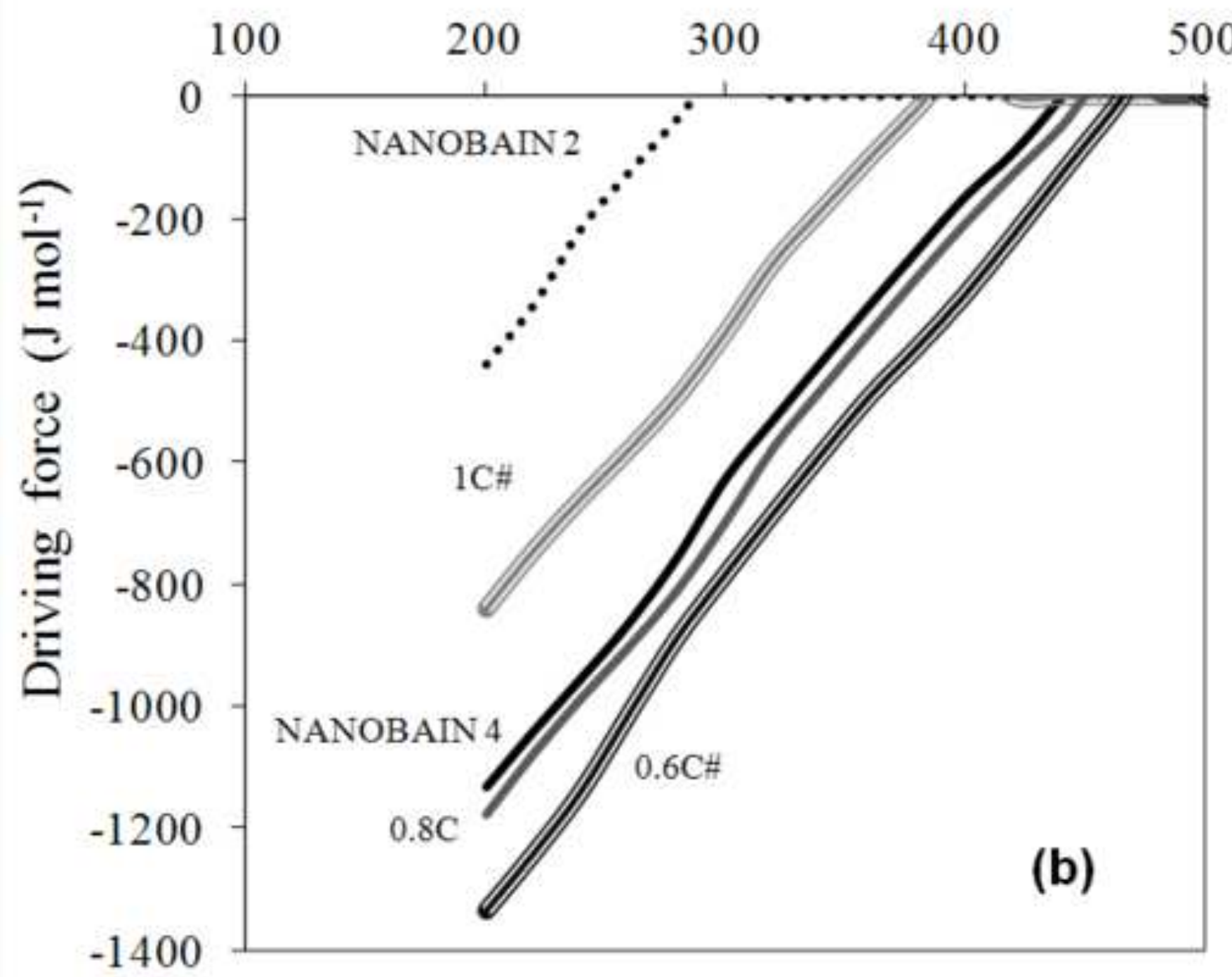

Figure 5. Theoretical calculations for the selected alloys in comparison with the reference alloys: (a) BS and MS critical transformation temperatures and (b) driving force for diffusionless transformation 


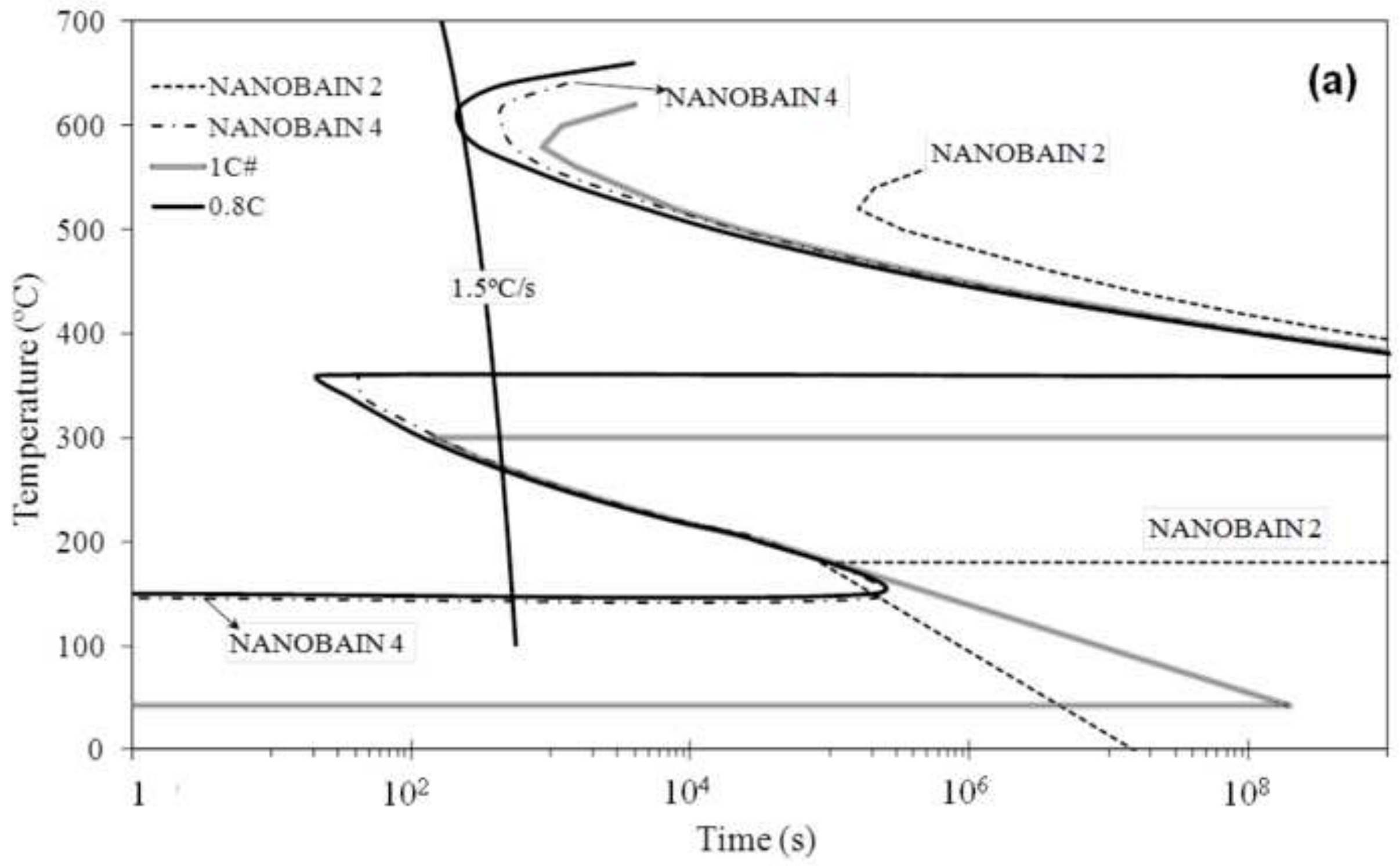

Figure 6. Theoretical TTT diagrams for the proposed alloys as compared with the reference ones, also represented the critical cooling rate in order to avoid formation of ferrite/pearlite previous to bainite transformation.............. 


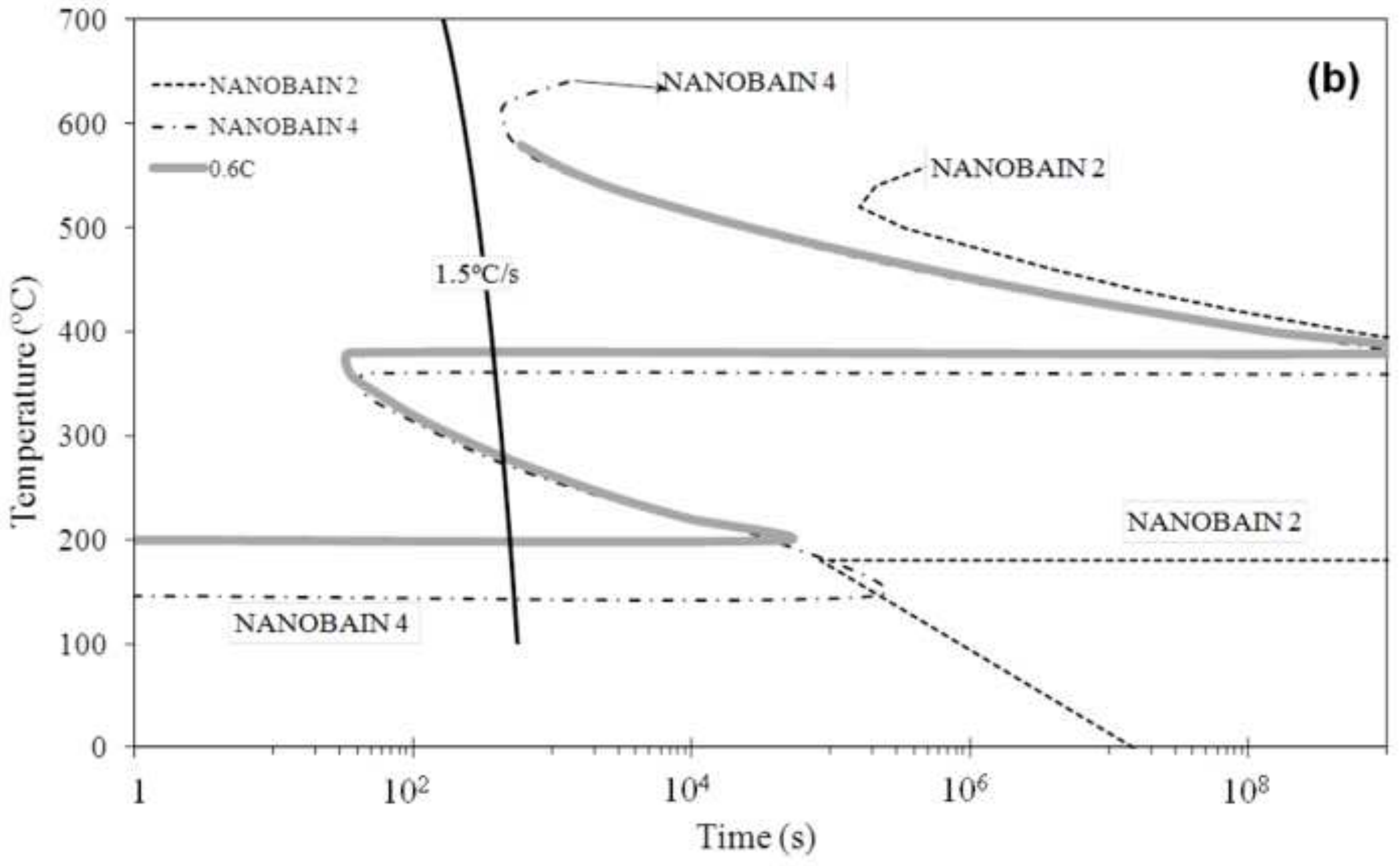

Figure 6. Theoretical TTT diagrams for the proposed alloys as compared with the reference ones, also represented the critical cooling rate in order to avoid formation of ferrite/pearlite previous to bainite transformation....... 


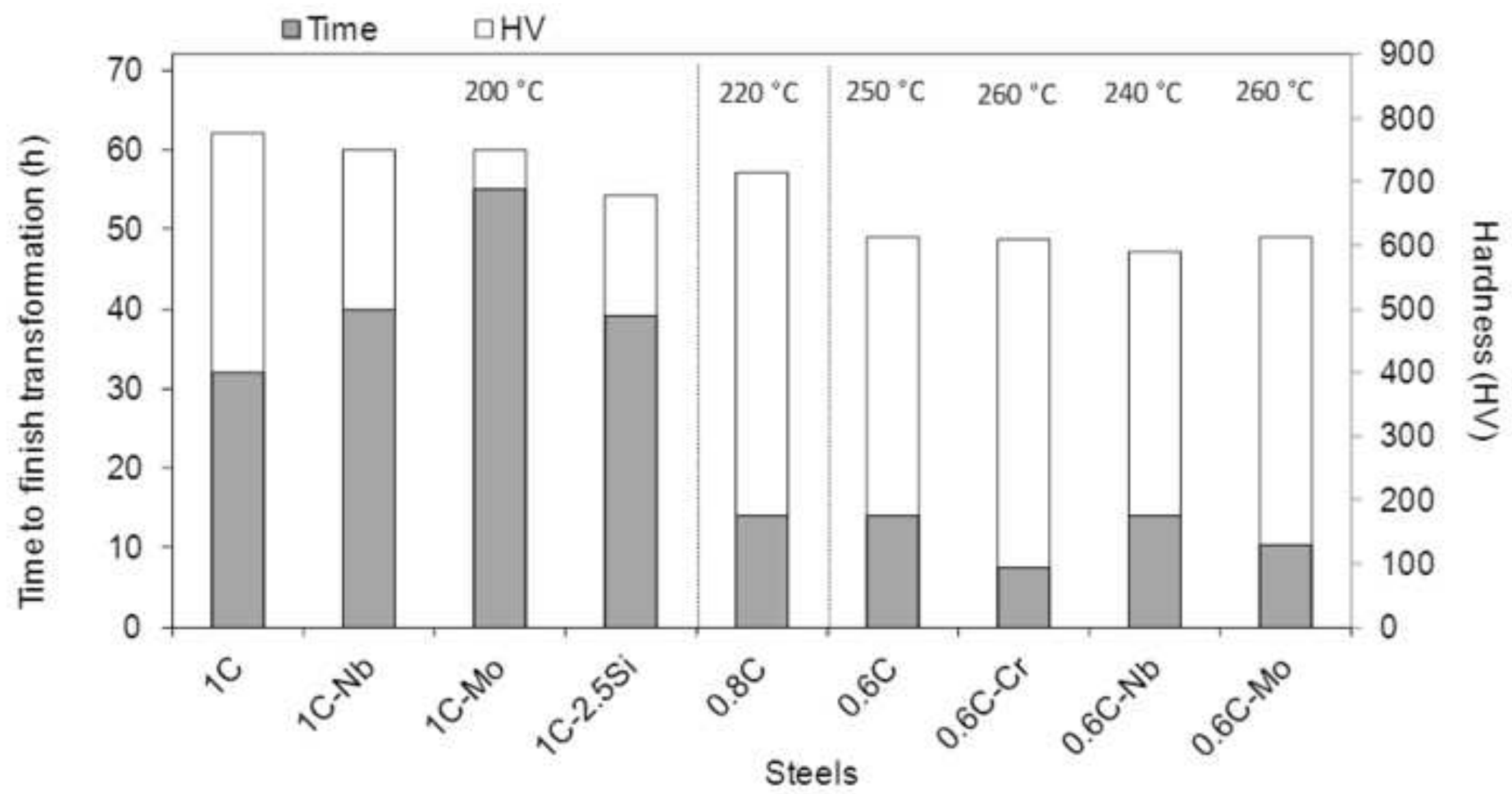

Figure 7. Time to end bainitic transformation al the lowest tested temperature, indicated at the top of the graph, and their corresponding HV. Hardness values represents the mean value of at least three measurements, with a typical variation of only $\pm 10 \mathrm{HV}$. 


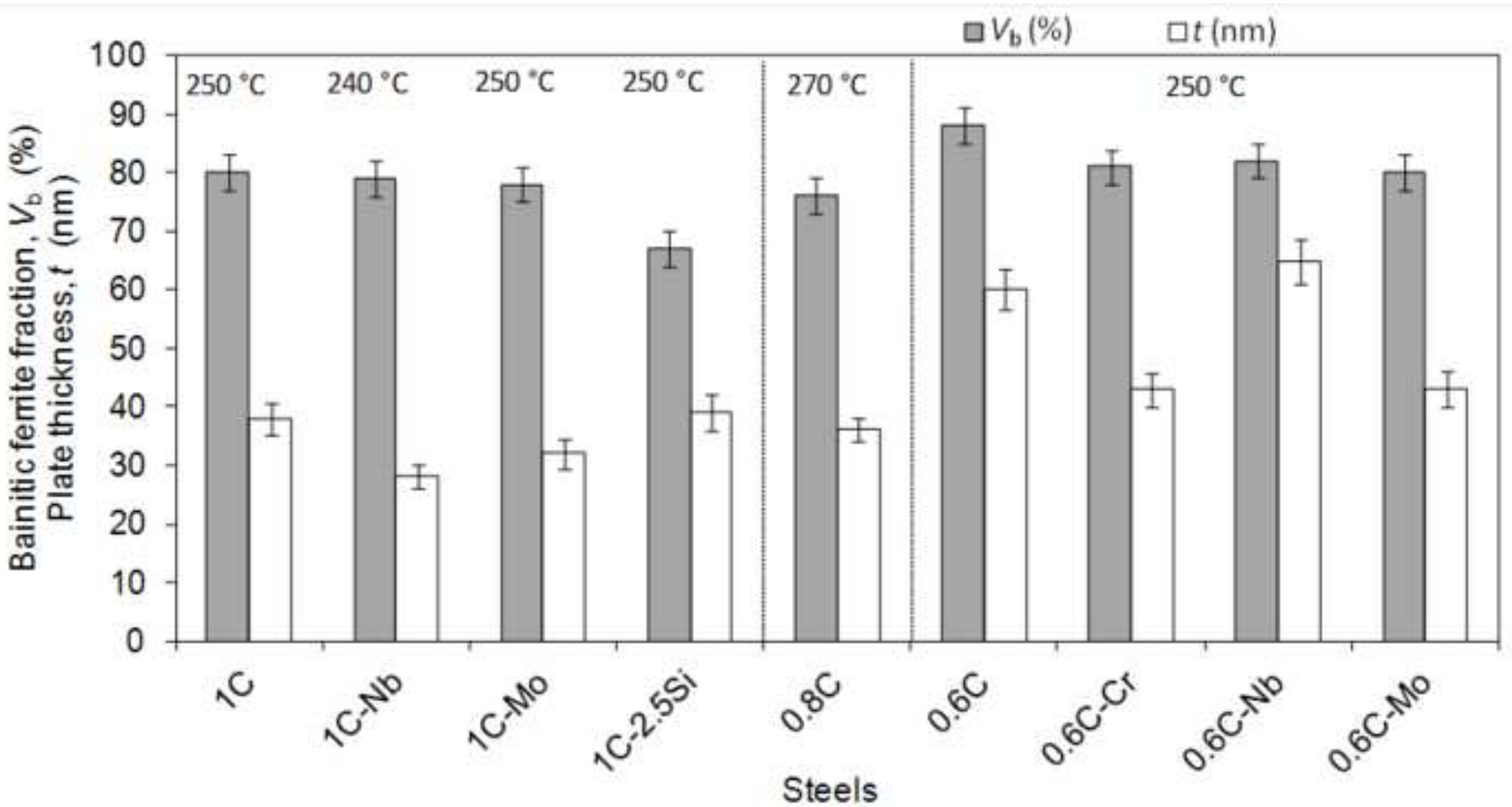

Figure 9. Fraction of bainitic ferrite and measured bainitic ferrite plate thickness 
Table 1. Chemical compositions of the first generation of NANOBAIN steels, wt.\%, and experimental $M_{\mathrm{S}}$ and $B_{\mathrm{S}}$ temperatures in ${ }^{\circ} \mathrm{C}^{\circ} \mathrm{C}$.

\begin{tabular}{ccccccccccc}
\hline Steel & $\mathrm{C}$ & $\mathrm{Si}$ & $\mathrm{Mn}$ & $\mathrm{Cr}$ & $\mathrm{Mo}$ & $\mathrm{V}$ & $\mathrm{Co}$ & $\mathrm{Al}$ & $M_{\mathrm{S}}$ & $B_{\mathrm{S}}$ \\
\hline NANOBAIN 1 & 0.78 & 1.59 & 1.94 & 1.33 & 0.30 & 0.11 & --- & --- & 120 & 325 \\
\hline NANOBAIN 2 & 0.98 & 1.46 & 1.89 & 1.26 & 0.26 & 0.09 & -- & -- & 125 & 335 \\
\hline NANOBAIN 3 & 0.83 & 1.57 & 1.98 & 1.02 & 0.24 & -- & 1.54 & -- & 120 & 360 \\
\hline NANOBAIN 4 & 0.78 & 1.49 & 1.95 & 0.97 & 0.24 & -- & 1.60 & 0.99 & 155 & 380 \\
\hline
\end{tabular}

Table 2. Quantitative experimental data of the first generation of NANOBAIN steels. $V_{\mathrm{b}}$ is the volume fraction of bainitic ferrite, the remainder of the microstructure being retained austenite. $T$ stands for the isothermal transformation temperature, and Time to that needed to finish the transformation, $t$ is the stereologically corrected value of the bainitic ferrite plate thickness [1-_3].

\begin{tabular}{cccccc}
\hline Steel & $T\left({ }^{\circ} \mathrm{C}\right)$ & Time $(\mathrm{h})$ & $t(\mathrm{~nm})$ & $V_{\mathrm{b}}(\%)$ & $\mathrm{HV}$ \\
\hline \multirow{3}{*}{ NANOBAIN 1 1 } & 300 & 26 & --- & 65 & 448 \\
\cline { 2 - 6 } & 250 & 72 & --- & 84 & 575 \\
\cline { 2 - 6 } & 200 & 216 & --- & 87 & 648 \\
\hline \multirow{3}{*}{ NANOBAIN 2 } & 300 & 36 & 124 & 55 & 420 \\
\cline { 2 - 6 } & 250 & 84 & 55 & 63 & 550 \\
\cline { 2 - 6 } & 200 & 216 & 35 & 69 & 619 \\
\hline \multirow{3}{*}{ NANOBAIN 3 } & 300 & 10 & 64 & 75 & 500 \\
\cline { 2 - 6 } & 250 & 14 & 49 & 79 & 589 \\
\cline { 2 - 6 } & 200 & 72 & 30 & 87 & 660 \\
\hline \multirow{3}{*}{ NANOBAIN 4 } & 300 & 8 & 52 & 63 & 500 \\
\cline { 2 - 6 } & 250 & 10 & 41 & 79 & 565 \\
\cline { 2 - 6 } & 200 & 72 & 45 & 83 & 650 \\
\hline
\end{tabular}

Table 3. Chemical composition of proposed alloys (wt.\%).

\begin{tabular}{ccccccc}
\hline Steel & $\mathrm{C}$ & $\mathrm{Si}$ & $\mathrm{Mn}$ & $\mathrm{Cr}$ & $\mathrm{Mo}$ & $\mathrm{Nb}$ \\
\hline $1 \mathrm{C}$ & 1.00 & 1.50 & 0.75 & 0.50 & --- & --- \\
\hline $1 \mathrm{CNb}$ & 1.00 & 1.50 & 0.75 & 0.50 & --- & 0.03 \\
\hline $1 \mathrm{CMo}$ & 1.00 & 1.50 & 0.75 & 0.50 & 0.1 & --- \\
\hline $1 \mathrm{CSi}$ & 1.00 & 2.50 & 0.75 & 0.50 & --- & --- \\
\hline $0.8 \mathrm{C}$ & 0.80 & 1.50 & 0.75 & 0.50 & --- & --- \\
\hline $0.6 \mathrm{C}$ & 0.60 & 1.50 & 1.25 & 1.50 & --- & --- \\
\hline $0.6 \mathrm{CCr}$ & 0.60 & 1.50 & 0.75 & 2.50 & --- & --- \\
\hline $0.6 \mathrm{CNb}$ & 0.60 & 1.50 & 1.25 & 1.50 & --- & 0.03 \\
\hline $0.6 \mathrm{CMo}$ & 0.60 & 1.50 & 1.25 & 1.50 & 0.1 & --- \\
\hline
\end{tabular}

